\title{
Information Content Capabilities of Very High Resolution Optical Space Imagery for Updating GIS Database
}

\author{
Mehmet Alkan*a, Karsten Jacobsen ${ }^{\mathrm{b}}$ \\ ${ }^{a}$ Yildiz Technical University, Davutpasa Campus, Dept. of Geomatics, 34220 Istanbul, Turkey ; \\ ${ }^{b}$ Leibniz Hannover University, Neinburger Street, Institute of Photogrammetry and Geoinformation, \\ Hannover, Germany.
}

\begin{abstract}
Nowadays, the number and capacity of very high resolution optical satellites grows permanently, so the access to very high resolution space images is not any more a problem. The use of Geographic Information Systems (GISs) together with Remote Sensing became important. With the increased ground resolution a competition to aerial images exist. For the generation of topographic maps, today available as GIS, the accuracy and the information content - what elements can be identified in the image - are important. Both may limit the presentation scale of topographic maps. As horizontal accuracy $0.25 \mathrm{~mm}$ up to $0.3 \mathrm{~mm}$ in the map scale are accepted. The required information content is more complicate. The object details to be presented in topographic maps vary from area to area which is based on the planned and unplanned areas. In this study, images from IRS-1C, Kompsat-1, SPOT 5, OrbView-3, IKONOS, QuickBird and WorldView-1 have been used for topographic mapping. For this reason, Zonguldak test fields are an important area for applications of the high resolution imageries. The details which can be identified in the space images dominantly depends upon the ground resolution, available as ground sampling distance (GSD). In this study, high resolution imageries have been tested depending on the GSD and corresponding to the map scales for updating GIS database.
\end{abstract}

Keywords: Mapping, Information Content, GIS

\section{INTRODUCTION}

In recent years, after the launch of very high resolution optical satellites, a new era of Earth observation began $[1,2]$. Very high resolution (VHR) optical satellite imagery have been used for several applications such as object extraction, change detection, topographic map production, and development of Geographic Information Systems (GIS). One of the important applications is the generation and updating of GIS databases by topographic mapping which depends on the presentation scale $[3,4,5,6]$. Up to date, the number and capacity of very high resolution optical satellites grows permanently, so the access to very high resolution space images is not any more a problem. The use of Geographic Information Systems (GISs) together with remote sensing information became important $[1,4,7]$. Because of the very high resolution of optical space imageries they can be used instead of aerial imagery depending upon the required information contents and accuracy $[4,7,8,9,10]$.

For the area of Zonguldak city, Turkey, beside other space imagery, images from IRS-1C, Kompsat-1, SPOT 5, OrbView-3, IKONOS, QuickBird, WorldView-1, Worldview-3 and GeoEye images are available and have been used for topographic mapping. Traditionally the mapping was based on aerial images being difficult because of legal classification limitations in Turkey. With the today available very high resolution space images with up to $0.31 \mathrm{~m}$ ground sampling distance (GSD) it is possible to use space images instead of aerial images. They have the advantage of simple availability and are not restricted by classification $[4,11]$.

In this study, Zonguldak city, located in North-West Turkey, has been selected as test area. It is the most important coal mining area of Turkey with not negligible subsidence. The area has a rolling up to mountainous topography even in the city. Caused by steep terrain with inclination down to North direction, shadows partially cause problems for object

Image Sensing Technologies: Materials, Devices, Systems, and Applications II, edited by Nibir K. Dhar, Achyut K. Dutta, Proc. of SPIE Vol. 9481, 94810K

(C) 2015 SPIE · CCC code: 0277-786X/15/\$18 · doi: 10.1117/12.2177857 
identification especially in the city. The average terrain inclination is $23 \%$. Figure 1 gives an overview about the built up area.

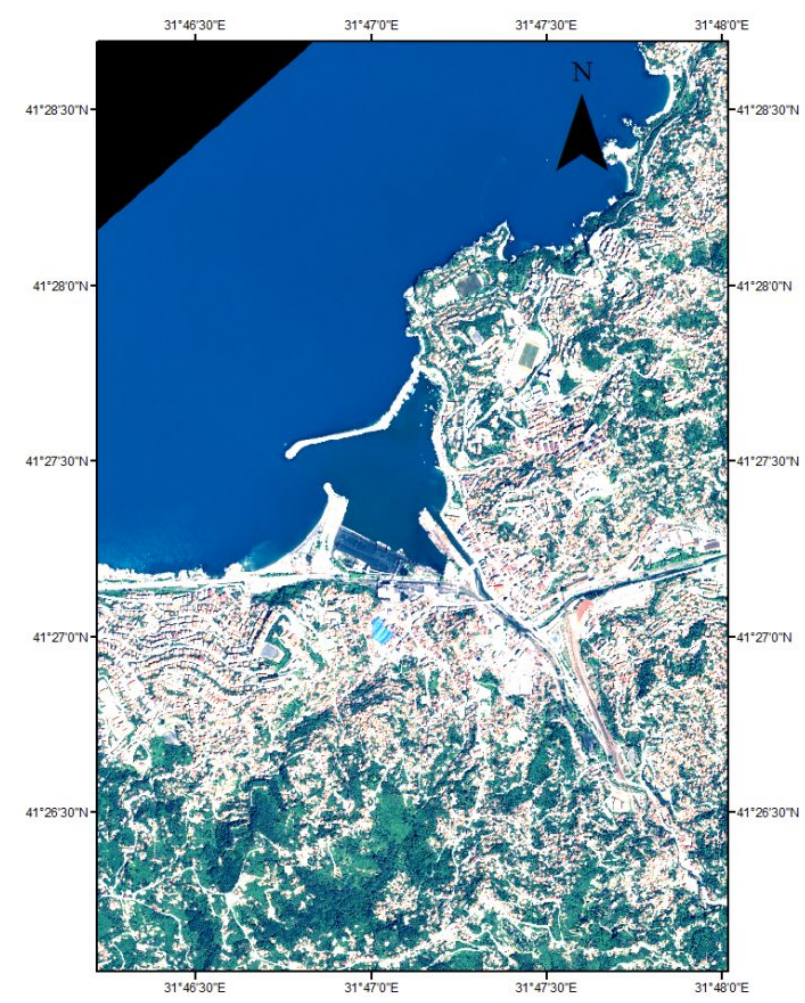

Figure 1. Test site on Quickbird pan-sharpened VHR satellite imagery

\section{NOMINAL RESOLUTION AND EFFECTIVE GSD}

Ground sampling distance is the distance of the centers of neighbored pixels projected to the ground. The smaller the GSD the more detailed information can be extracted. For instance, more objects details can be seen in the very high resolution Worldview-1 images with $0.5 \mathrm{~m}$ GSD as in SPOT-5 images with 5m GSD (figure 2). In SPOT-5 images only large buildings can be recognized while Worldview-1 images show even details at small buildings. Similar details as in WorldView-1 images can be seen in Quickbird scenes, while IKONOS images are still affected by the larger GSD (figure 3.). The nominal ground resolution must not be identical to the effective; especially space images with staggered CCDs (50\% oversampling) may have a lower image quality, leading to reduced effective ground resolution. The effective GSD can be analyzed by edge detection [12].

Neighbored pixels may be over-sampled or under-sampled. For instance, SPOT 5 generates Supermode images with $2.5 \mathrm{~m}$ GSD based on $5 \mathrm{~m}$ projected pixel size. Generally the nominal GSD may not correspond to the information contents expressed by the effective GSD. Table 1 shows the result of an edge analysis; with the exception of the analogue KVR 1000 , the nominal resolution corresponds for the used images to the effective resolution (Table 2). 


\section{COMPARISION OF IMAGERY AND INFORMATION CONTENT}

Table 1. Nominal and effective GSD determined by edge analysis

\begin{tabular}{|l|c|c|c|}
\hline & $\begin{array}{c}\text { SNR (Signal to } \\
\text { noise relation) }\end{array}$ & $\begin{array}{c}\text { Nominal pixel } \\
\text { size }(\mathrm{m})\end{array}$ & $\begin{array}{c}\text { Effective pixel size } \\
(\mathrm{m})\end{array}$ \\
\hline SPOT 5 & $41(8$ bit image $)$ & 5 & 5 \\
\hline KOMPSAT-1 & $12(8$ bit image $)$ & 6.6 & 6.6 \\
\hline IKONOS & $105(16$ bit image $)$ & 1 & 1 \\
\hline Quickbird & $119(16$ bit image $)$ & 0.6 & 0.6 \\
\hline Worldview-1 & $69(16$ bit image $)$ & 0.5 & 0.5 \\
\hline Pleiades & $106(16$ bit image $)$ & 0.5 & 0.5 \\
\hline
\end{tabular}

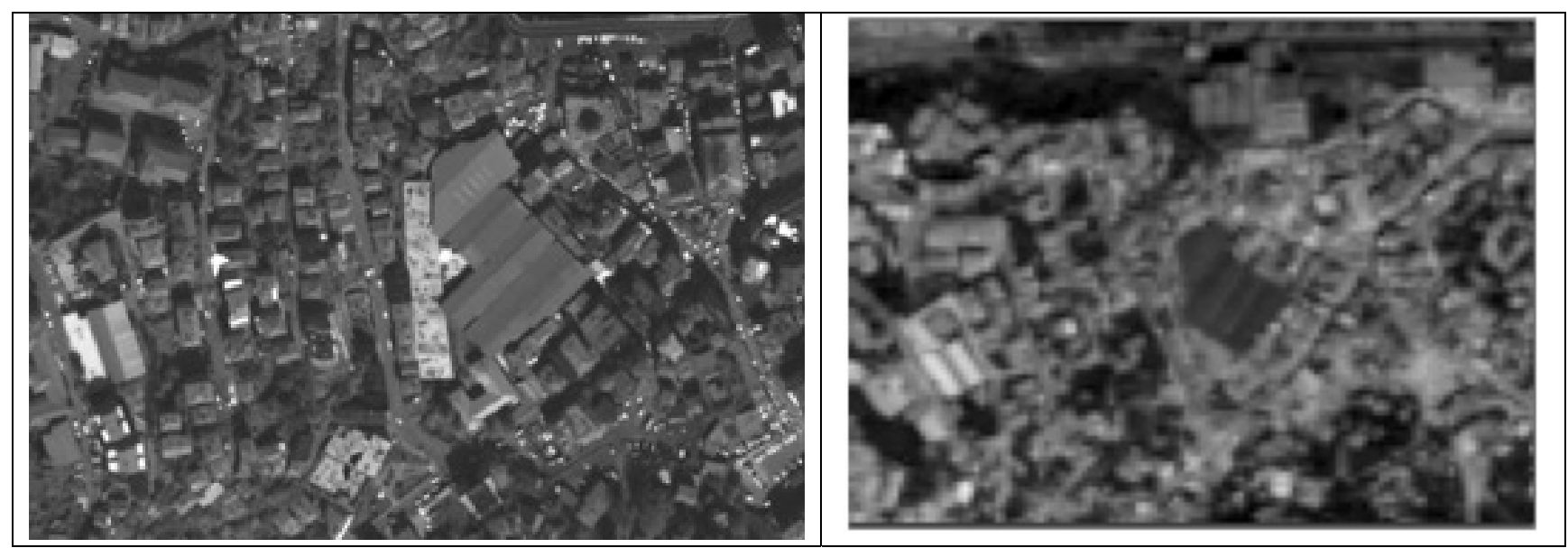

Figure 2. Panchromatic Worldview-1 image (left), SPOT-5 panchromatic image of a Zonguldak downtown area (right)

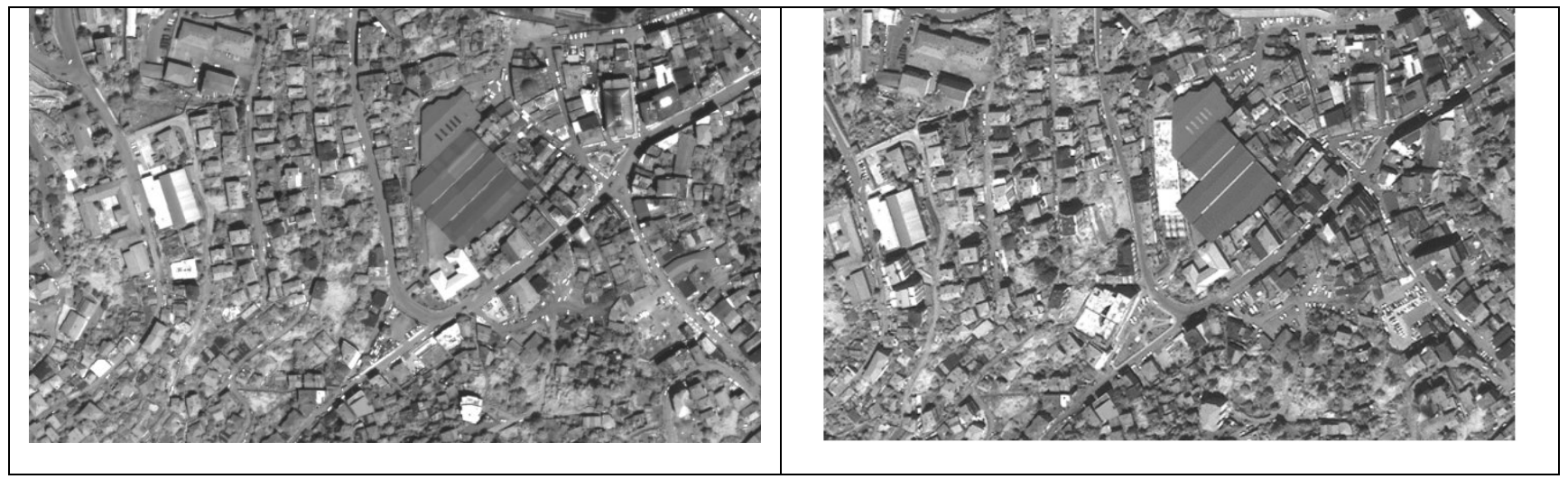

Figure 3. Panchromatic Quickbird image (left), panchromatic IKONOS image - same area (right) 
In figure 4 windows of space images with approximately the same number of pixels from the city area of Zonguldak can be compared. The dominating factor for the object identification is the GSD, but the color simplifies the interpretation. A simple comparison of the different space images gives a good impression about the information contents. SPOT 5 with $5 \mathrm{~m}$ GSD allows the identification of larger buildings, but it is not easy to extract it. On the other hand IKONOS, Quickbird and Worldview-1 imageries have with $1 \mathrm{~m}$ and below a satisfying GSD for the identification and mapping of buildings, with Quickbird and Worldview-1 the mapping of building extensions is simpler as with IKONOS.

The pan-sharpened IKONOS image in figure 4 is affected by shadows. Because of this, especially road network extraction is very difficult in the narrow and inclined streets. The better ground resolution of Quickbird and the higher sun elevation simplifies the object extraction. Even with 2.4m GSD in Quickbird color imageries the buildings can be seen without problems (figure 5). The $0.5 \mathrm{~m}$ GSD of Worldview-1 simplifies the mapping of buildings (Figure 6). The VHR IKONOS, QuickBird and Worldview-1 images with $1 \mathrm{~m}, 0.6 \mathrm{~m}$ and $0.5 \mathrm{~m}$ GSD, enable a competition to aerial images. QuickBird images can be compared with aerial images having a scale of 1:30 000, allowing the detailed mapping of building extensions. A major advantage of the multispectral bands is the improved potential for object recognition and interpretation. Figure 5, 6 and 7 show the on-screen vectorization results with IKONOS, QuickBird and Worldview-1 panchromatic and pan-sharpened images, allowing mapping up to the topographic map scale of $1: 10000$ respectively 1:5000.

As summary for topographic mapping and updating with very high resolution optical space imagery, the required GSD for the identification of object types in panchromatic images are listed in table 2 . The rule of thumb of 0.05 up to $0.1 \mathrm{~mm}$ pixel size in the map scale has been confirmed. Most details required for the map scale 1:10000 have been identified in the build-up areas. The required higher degree of details for mapping in 1:5000 can be extracted from WorldView-1 images with $0.5 \mathrm{~m}$ GSD as well as from the $0.61 \mathrm{~m}$ GSD of Quickbird.

Table 2. Required GSD for topographic mapping based on panchromatic images

\begin{tabular}{|l|l|l|}
\hline Objects & $\begin{array}{l}\text { Required pixel } \\
\text { size }\end{array}$ & Map Scale \\
\hline Buildings and roads & $0.6 \mathrm{~m}$ or lower GSD & $1: 5000$ \\
\hline Railway & $0.6 \mathrm{~m}$ or lower GSD & $1: 5000$ \\
\hline Buildings and roads & $1.0 \mathrm{~m}$ GSD & $1: 10.000$ \\
\hline Railway, minor networks & $1.0 \mathrm{~m}$ GSD & $1: 10.000$ \\
\hline $\begin{array}{l}\text { Building blocks, major road } \\
\text { network }\end{array}$ & $2.0 \mathrm{~m}$ GSD & $1: 25.000$ \\
\hline
\end{tabular}




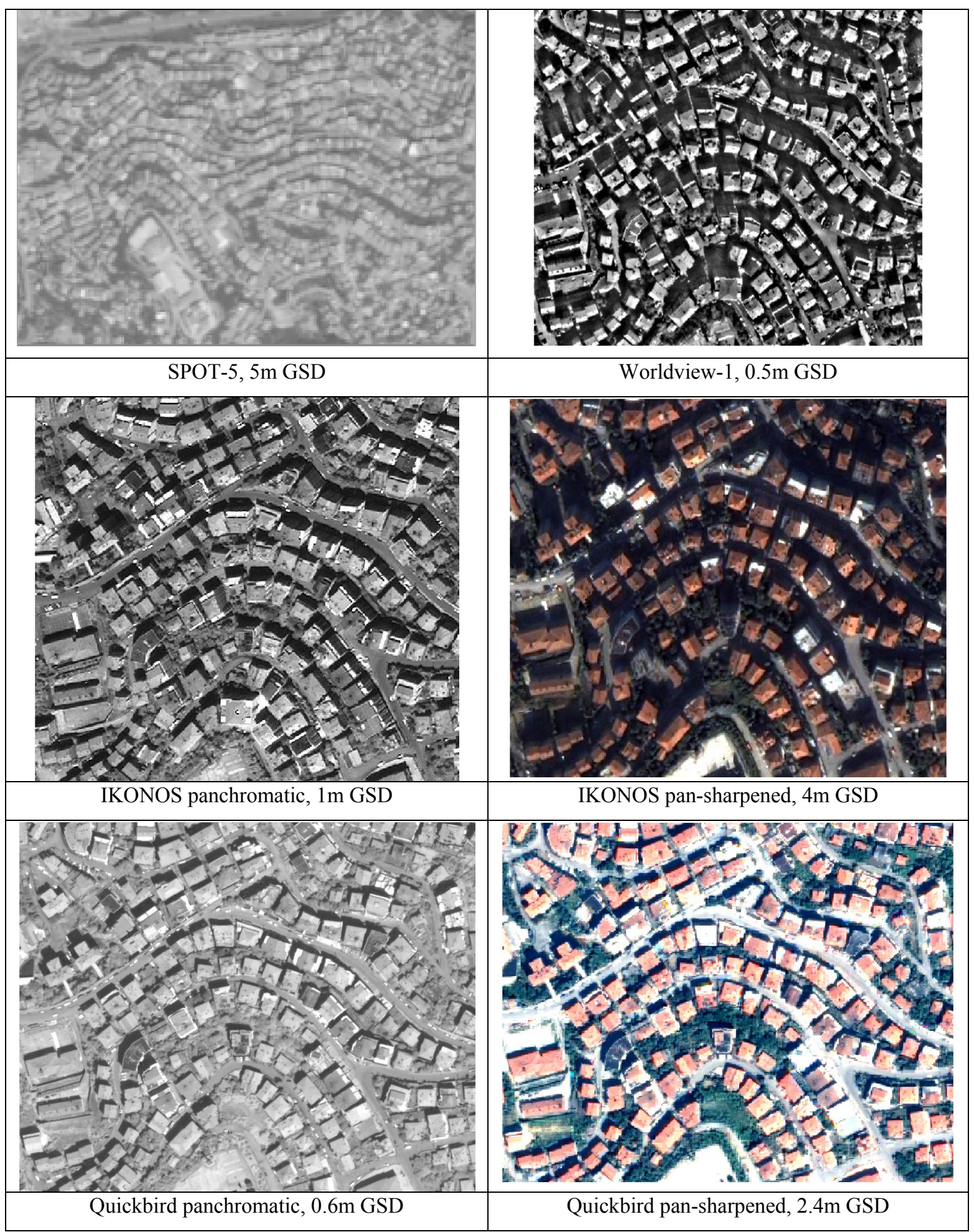

Figure 4. Very high resolution space images of Zonguldak test area 


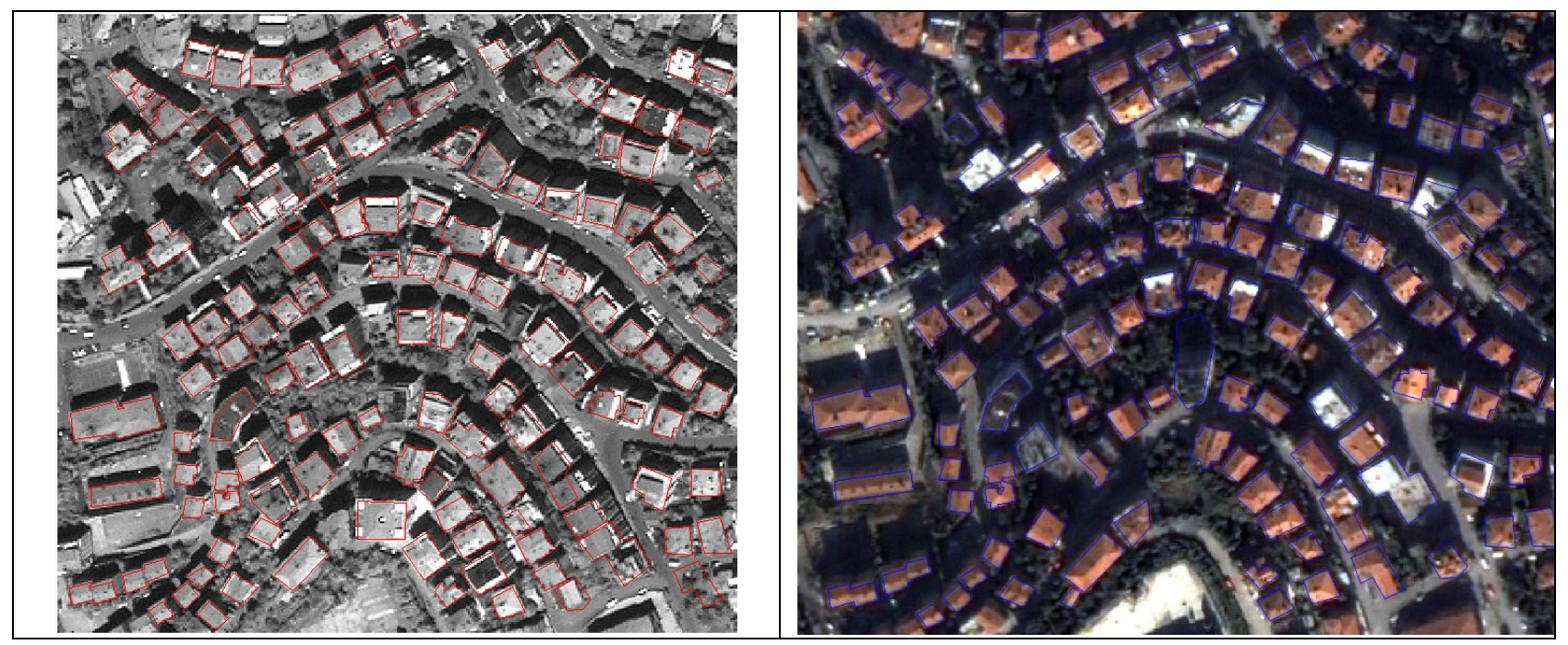

Figure 5. Object extraction from IKONOS pan and pan-sharpened images

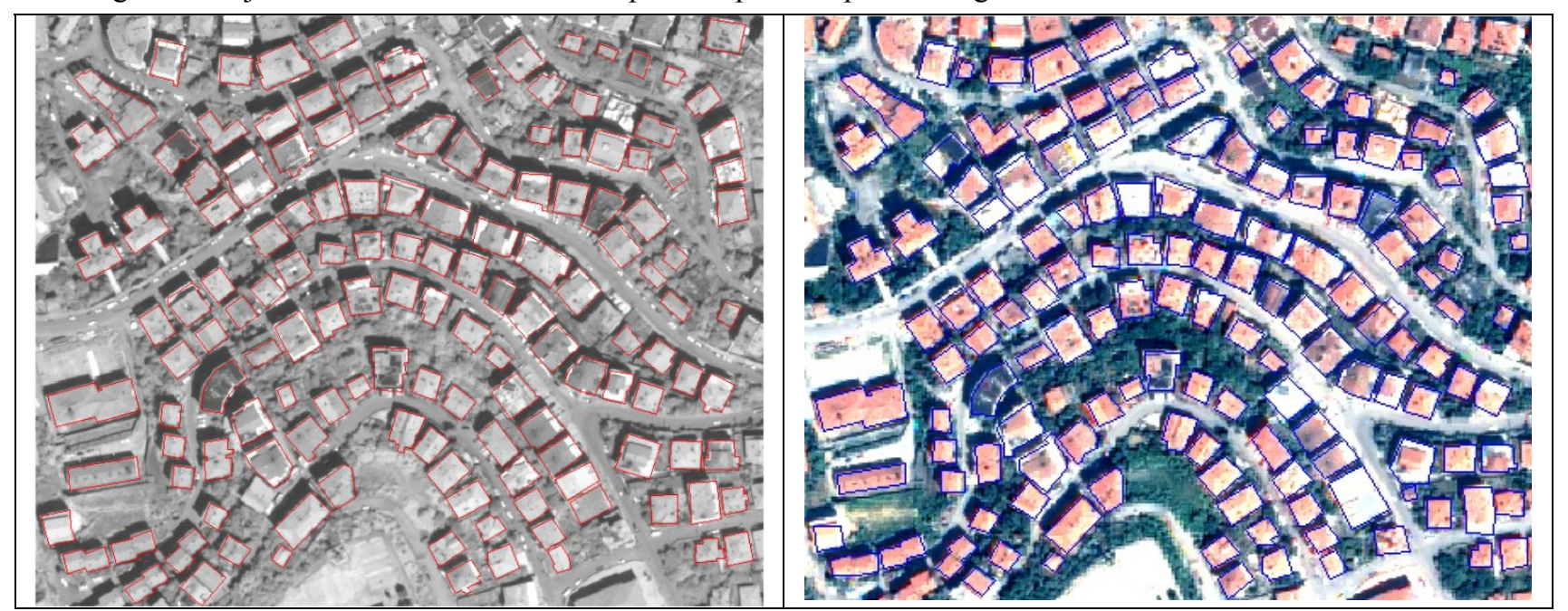

Figure 6. Object extraction from Quickbird pan and pan-sharpened images

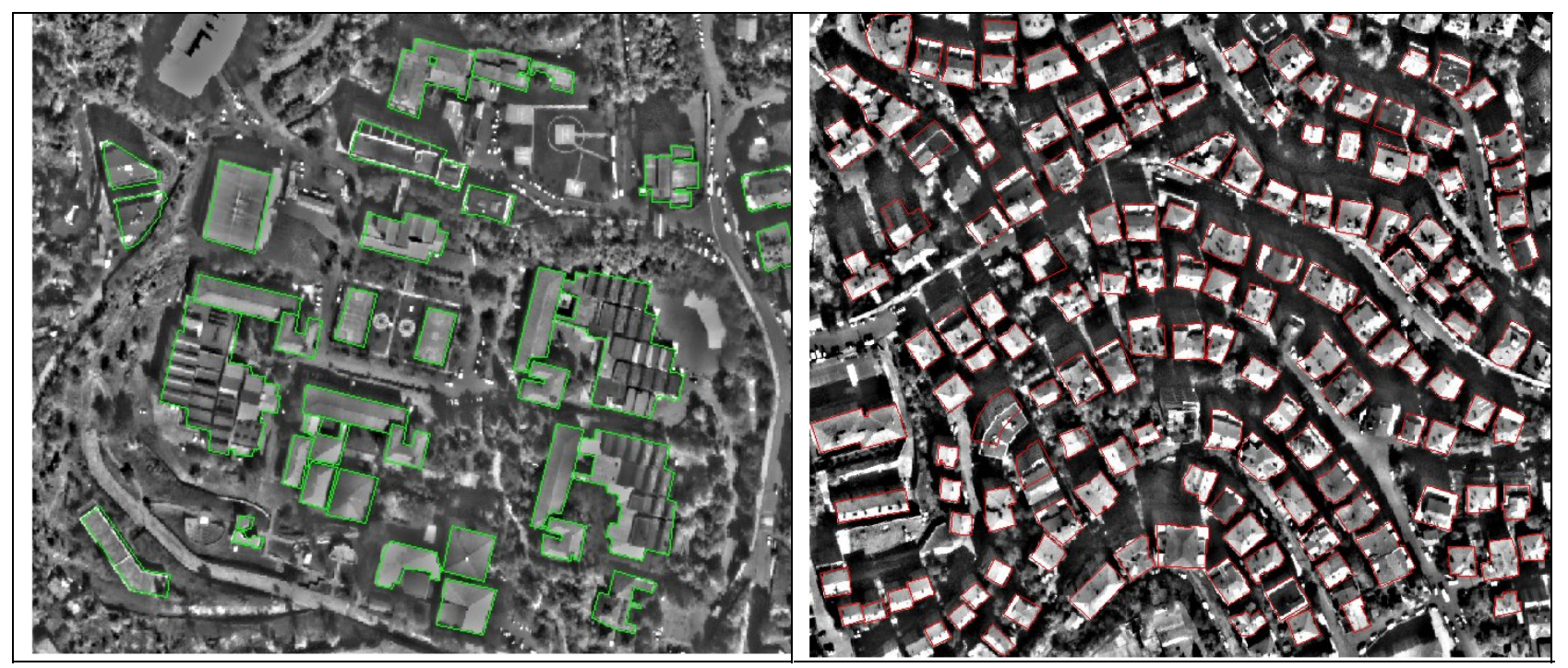

Figure 7. Object extraction from Worldview-1 image in the area of the Zongulak University (left) and a build up area (right) 


\section{CONCLUSION}

In this study, the suitability of VHR panchromatic and color images for mapping purposes and updating GIS has been evaluated. The information content of images was analyzed for built up areas of Zonguldak test site. The panchromatic and color images scenes have a ground resolution also typical for aerial images. The required accuracy of $0.25 \mathrm{~mm}$ in the publishing scale can be reached without problems. As the limiting factor for mapping purposes the information content is obvious. The generally required production scale of 0.05 to $0.1 \mathrm{~mm}$ GSD in the map scale has been confirmed. This corresponds to a topographic map scale of 1:10,000 respectively 1:5000 for $1 \mathrm{~m}$ and $0.5 \mathrm{~m}$ GSD images. With color images the interpretation is easier, but no additional details can be extracted in relation to panchromatic images.

Finally, the extracted buildings clearly demonstrate that IKONOS, Quickbird and WorldView- 1 images, with $1 \mathrm{~m}, 0.61 \mathrm{~m}$ respectively $0.5 \mathrm{~m} \mathrm{GSD}$, can be used for mapping and map update for maps with a scale of 1:10.000 to 1:5000 in the used area.

\section{REFERENCE LINKING}

[1] Alkan, M., Buyuksalih G., Sefercik U.G, and Jacobsen J., "Geometric accuracy and information content of Worldview-1 images", Optical Engineering Papers, 52(2): 026201-1 and 026201-7 (2013).

[2] Li R.., "Potential of High-Resolution Satellite Imagery for National Mapping Products", Photogrammetric Engineering \& Remote Sensing Papers, 64(12), 1165-1169, (1998).

[3] Jacobsen K., "Comparison of High Resolution Mapping from Space", Proc. INCA workshop, (2002), unpaginated CD-ROM.

[4] Jacobsen, K., Buyuksalih G., and I. Baz, "Mapping From Space for Developing Countries", Proc. EARSeL Joint Workshop: Remote Sensing - New Challenges of High Resolution, (2008), unpaginated CD-ROM.

[5] Ahmadi S., Valadan Zoej M.J., Ebadi H., Moghaddam H.A., and Ali M., “Automatic urban building boundary extraction from high resolution aerial images using an innovative model of active contours", International Journal of Applied Earth Observation and Geoinformation Papers, 12(3): 150-157, (2010).

[6] Mondino E. B., and Chiabrando F., "GeoEye vs. QuickBird: operational potentialities, limits, and integration for fast map production", Proc. SPIE 7831, 78310F (2010) [DOI: http://dx.doi.org/10.1117/12 .865006].

[7] Topan, H., Buyuksalih G., and Jacobsen K., "Information Contents of High Resolution Satellite Images", Proc. EARSeL Workshop on 3D Remote Sensing, (2005), unpaginated CD-ROM.

[8] Alkan, M., Sefercik U.G, Marangoz A.M., and Karakis S., "Updating Object for Topographic Map Information Using High Resolution Satellite Images of Zonguldak Testfield”, Proc. 30th EARSeL Symposium, Remote Sensing for Science, Education and Culture, (2010).

[9] Topan, H., Maktav D., Jacobsen K., and Buyuksalih G., "Information Content of Optical Satellite Images for Topographic Mapping”, International Journal of Remote Sensing Papers, 30(7): 1819-1827, (2009).

[10] Aguilar, M.A., Aguilar F.J., and Agüera F., "Assessing geometric reliability of corrected images from very high resolution satellites", Photogrammetric Engineering \& Remote Sensing Papers, 74(12):1551-1560, (2008).

[11] Buyuksalih, G., Jacobsen K., and Baz I., "Determination of the build up area development in the Greater Municipality of Istanbul by space images", Proc. EARSel Workshop Remote Sensing - New Challenges of High Resolution, (2008), unpaginated CD-ROM.

[12] Jacobsen, K., "Tells the number of pixels the truth? - Effective Resolution of Large Size Digital Frame Cameras", Proc. ASPRS 2008 Annual Convention, Portland, (2008), unpaginated CD-ROM. 